\title{
Fontan Operation and the Cavopulmonary Technique. Immediate and Late Results According to the Presence of Atrial Fenestration
}

\author{
Edmar Atik, Nana Miura Ikari, Tamara Cortez Martins, Miguel Barbero-Marcial \\ São Paulo, SP - Brazil
}

Objective - To compare immediate and late results in patients with or without fenestration who underwent cavopulmonary anastomosis so that we could assess the efficiency of the technique.

Methods - Sixty-two patients underwent surgery between 1988 and 1999, 41 with fenestration (group I-G I) and 21 withoutfenestration (group II -G II). Tricuspid atresia was prevalent in group I (23-56\%) and single ventricle was prevalent in group II (14-66\%). Mean ages at the time of operation were 7.3 years in group I and 7.6 in group II. At late follow-up, mean ages were 10.6 years in group I and 12.8 years in group II.

Results - Immediate and late mortality were 7.3\% in G-I and $4.7 \%$ in G-II. Significant pleural effusion occurred in 41.4\% of G-Ipatients and in 23.8\% of G-II patients. Significant pericardial effusion occurred in $29.2 \%$ and $14.2 \%$, respectively, in groups I and II. Central venous pressure was greater in

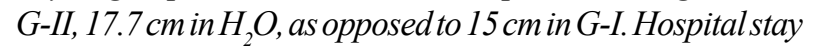
was similar between the groups, 26.3 and 21.8 days, respectively. Cyanosis and arterial insaturation occurred in $5 \mathrm{pa}$ tients, and 4 patients were in functional class II, all from G-I. At latefollow-up, 58 (93.5\%) were in functional class I. Sinus rhythm was present in $94 \%$, and pulmonary perfusion was similar in both groups. Eleven patients who underwent spirometry had good tolerance to physical effort.

Conclusion - Atrial fenestration did not improve the immediate or latefollow-up of patients who underwent cavopulmonary anastomosis, and is, therefore, dispensable.

Keywords: Fontan technique, cavopulmonary anastomosis, fenestration

Instituto do Coração do Hospital das Clínicas - FMUSP

Mailing address: Edmar Atik - InCor - Dr. Av. Enéas C. Aguiar, 44 - 05403-900

São Paulo, SP - Brazil - E-mail: conatik@incor.usp.br

Received for publication on $7 / 12 / 00$

Accepted on $31 / 1 / 01$
Cavopulmonary anastomosis became the most common alternative to the Fontan operation for correcting cardiopathies that cannot be treated anatomically, especially tricuspid atresia and single ventricle ${ }^{1-3}$.

Other technical modifications seem to have improved immediate results with atrial fenestration ${ }^{4}$ and late results with the placement of extracardiac tubes ${ }^{5}$, rather than with an intraatrial tunnel.

A better long-term follow-up of this corrective operation is also associated with an earlier intervention in the absence of factors that favor greater ventricular dysfunction ${ }^{6}$.

Aiming at proving such findings, we compared early and late results in patients who underwent this technique, with or without fenestration, primarily so that we could estimate the efficiency of this action.

\section{Methods}

Sixty-two patients underwent total cavopulmonary anastomosis between August 23, 1988 and December 1, 1999 at the Instituto do Coração (InCor) (Heart Institute) of the Hospital das Clínicas of the FMUSP (University of São Paulo). Thirty ( $48.3 \%)$ were male and $32(51.6 \%)$ were female.

Regarding congenital heart anomalies (tab. I), 26 patients had tricuspid atresia, 23 with atrial fenestration. Twenty-five patients had single ventricle (right type in 9 and left type in 16), and, of these patients, 11 had atrial fenestration. Eleven patients had other congenital anomalies, 7 with atrial fenestration. Four patients of this 11 had double outlet right ventricle. Two patients had transposition of the great arteries with ventricular septal defect and hypoplasia of the right ventricle. Corrected transposition of the great arteries with left ventricle hypoplasia was present in 3 patients. Ebstein anomaly was present in 1 patient and atrioventricular septal defect with right ventricle hypoplasia was present in 1 patient.

Dextrocardia occurred in 5 (8\%) of the 62 patients, 4 with situs solitus and one with situs inversus. Associated car- 
diac abnormalities were corrected transposition of the great arteries in 1 , transposition of the great arteries in 1 , tricuspid atresia in 1 and single ventricle in 2 patients. Levocardia and situs inversus were present in 2 patients (3.2\%), 1 with corrected transposition of the great arteries and the other with single ventricle.

Absence of the left atrioventricular connection occurred in $4(6.4 \%)$ of the 62 patients, 3 with left ventricular prevalence and 1 with right ventricular prevalence. Asplenia occurred in 1 patient with right single ventricle.

All abnormalities were divided into 2 groups: those with atrial fenestration (group I - 41 cases) and those without (group II - 21 cases).

Previous Blalock-Taussig surgery was prevalent in patients with tricuspid atresia (17 of 26 patients) and in group I ( 21 of 41 patients). Pulmonary arterial banding was prevalent in patients with single ventricle ( 8 of 25) and in group II (5 of 21). Seven patients underwent previous bidirectional Glenn anastomosis, 5 of them with single ventricle and 5 were from group I.

Mean age at the time of operation was similar in both groups, $7.37 \pm 3.48$ years in group I and $7.6 \pm 4.63$ years in group II, and long-term mean age was greater in group II, $12.8 \pm 4.64$ years, and $10.6 \pm 5.03$ years in group $I$.

In 15 patients (11 of group I), an extracardiac conduit of plicate pericardium was placed between the inferior vena cava and the right pulmonary artery (tab. I).

The following were evaluated in both groups: mortality, immediate and late congestive events, cyanosis, arterial insaturation, long-term functional class, pulmonary perfusion, and physical activity.

All results were expressed in mean \pm standard deviation. Variables were compared using Fischer's exact test, with $P<0.05$ considered significant. However, the results had no statistical significance, so we decided just to mention them according to the percentage found.

\section{Results}

Two patients (3.2\%) from group I died immediately, one with tricuspid atresia and the other with single ventricle.
Two patients (3.3\%) died 1 year after the operation, 1 from each group, both with single ventricle. Death in these 4 patients was due to cardiac failure and congestive events caused by significant pleural and pericardial effusion (tab. I). All of them had had previous palliative operations and their ages were 7 years and 10 months and 21 years (the 2 patients who died immediately) and 5 years and 1 month and 8 years and 3 months in the 2 patients who died after 1 year.

Significant pleural effusion occurred in 17 (41.4\%) group I patients and in 5 (23.8\%) group II patients. Pericardial effusion, also significant, occurred in $12(29.2 \%)$ group I patients and in 3 (14.2\%) group II patients.

Nine group I patients (21.9\%) and 10 group II patients (47.6\%) did not have pleural effusion. Mild pleural effusion occurred in $13(31.7 \%)$ group I patients and in $5(23.8 \%)$ group II patients. No pericardial effusion occurred in 21 (51.2\%) group I patients and in 17 (80.9\%) group II patients.

Serosal volume effusion did not differ in the congenital cardiac anomalies (tab. II).

The occurrence of effusion was significant in patients undergoing previous palliative procedures, such as BlalockTaussig, bidirectional Glenn anastomosis, or pulmonary arterial band, when compared with the absence of such procedures (fig. 1).

Postoperative hospital stay duration was not significantly different between the groups. It was $26.2 \pm 22$ days in group I, with a variation of 7 to 103 days and $21.8 \pm 14$ days in group II, ranging from 7 to 52 days (tab. II).

Central venous pressure was slightly higher in the first 3 postoperative days in the group of patients without fenestration (mean $17.7 \mathrm{~cm} \mathrm{H}_{2} \mathrm{O}$ compared with $14.3 \mathrm{~cm} \mathrm{H}_{2} \mathrm{O}$ in the other group). Arterial oxygen saturation was 95 and $91 \%$, respectively, in both groups (fig. 2).

Of 62 patients studied, 57 (91.9\%) were in functional class I and 5 were in functional class II. At late follow-up, cyanosis and arterial oxygen insaturation occurred in $5 \mathrm{pa}-$ tients, all from group I, 4 patients had tricuspid atresia and 1 patient had single ventricle. Of 5 patients with functional class II, 4 were from group II, 2 of these had tricuspid atresia and 2 had single ventricle (tab. III).

Table I - Previous operation, age at the time of cavopulmonary technique and during follow-up, types of operation performed and mortality in relation to anatomy with and without atrial fenestration.

\begin{tabular}{|c|c|c|c|c|c|c|c|c|c|c|c|c|}
\hline \multirow[t]{2}{*}{ Diagnosis } & \multirow[t]{2}{*}{$\mathrm{N}$} & \multicolumn{3}{|c|}{ Previous Operation } & \multicolumn{2}{|c|}{ Age } & \multicolumn{2}{|c|}{ Atrial Tunnel } & \multicolumn{2}{|c|}{ Ext tube } & \multicolumn{2}{|c|}{ Death } \\
\hline & & Blalock & Glenn & Banding & Oper & FU & Fen & Nfen & Fen & Nfen & I & $\mathrm{L}$ \\
\hline Tricuspid atresia & 26 & 17 & 2 & 1 & & & 16 & 3 & 7 & - & & \\
\hline Fenestrated & 23 & 16 & 2 & 1 & 6.65 & 8.86 & & & & & 1 & - \\
\hline Nonfenestrated & 3 & 1 & - & - & 10.1 & 17.66 & & & & & & \\
\hline Single ventricle & 25 & 5 & 5 & 8 & & & 7 & 10 & 4 & 4 & & \\
\hline Fenestrated & 11 & 1 & 3 & 3 & 10.35 & 12.7 & & & & & 1 & 1 \\
\hline Nonfenestrated & 14 & 4 & 2 & 5 & 7.6 & 11.8 & & & & & - & 1 \\
\hline Others & 11 & 5 & - & 2 & & & 7 & 4 & - & - & & \\
\hline Fenestrated & 7 & 4 & - & 2 & 10.2 & 12.8 & & & & & - & - \\
\hline Nonfenestrated & 4 & 1 & - & - & 8.0 & 13.7 & & & & & - & - \\
\hline Total & 62 & 27 & 7 & 11 & & & & & & & 2 & 2 \\
\hline Fenestrated & 41 & 21 & 5 & 6 & 7.6 & 10.6 & & & & & 2 & 1 \\
\hline Nonfenestrated & 21 & 6 & 2 & 5 & 7.3 & 12.8 & & & & & - & 1 \\
\hline
\end{tabular}




\begin{tabular}{|c|c|c|c|c|c|c|c|c|}
\hline \multirow[t]{2}{*}{ Diagnosis } & \multirow[t]{2}{*}{$\mathrm{N}$} & \multicolumn{3}{|c|}{ Pleural effusion } & \multicolumn{2}{|c|}{ Pericardial effusion } & \multirow[b]{2}{*}{ Significant } & \multirow[t]{2}{*}{ Duration of hospital stay (days) } \\
\hline & & No & Mild & Significant & No & Mild & & \\
\hline Tricuspid atresia & 26 & 11 & 5 & 10 & 14 & 4 & 8 & \\
\hline Fenestrated & 23 & 8 & 5 & 10 & 11 & 4 & 8 & $25.1(7-103)$ \\
\hline Nonfenestrated & 3 & 3 & - & - & 3 & - & - & $14(13-16)$ \\
\hline Single ventricle & 25 & 6 & 9 & 8 & 17 & 3 & 4 & \\
\hline Fenestrated & 11 & 1 & 5 & 4 & 7 & 2 & 1 & $24.6(9-76)$ \\
\hline Nonfenestrated & 14 & 5 & 4 & 4 & 10 & 1 & 3 & $22.9(7-52)$ \\
\hline Others & 11 & 2 & 4 & 5 & & & & \\
\hline Fenestrated & 7 & - & 3 & 4 & 4 & - & 3 & $33.1(14-95)$ \\
\hline Nonfenestrated & 4 & 2 & 1 & 1 & 4 & - & - & $24(8-52)$ \\
\hline Total & 62 & 19 & 18 & 22 & 38 & 7 & 15 & \\
\hline Fenestrated & 41 & 9 & 13 & 17 & 21 & 6 & 12 & $26.2(7-103)$ \\
\hline Nonfenestrated & 21 & 10 & 5 & 5 & 17 & 1 & 3 & $21.8(7-52)$ \\
\hline
\end{tabular}

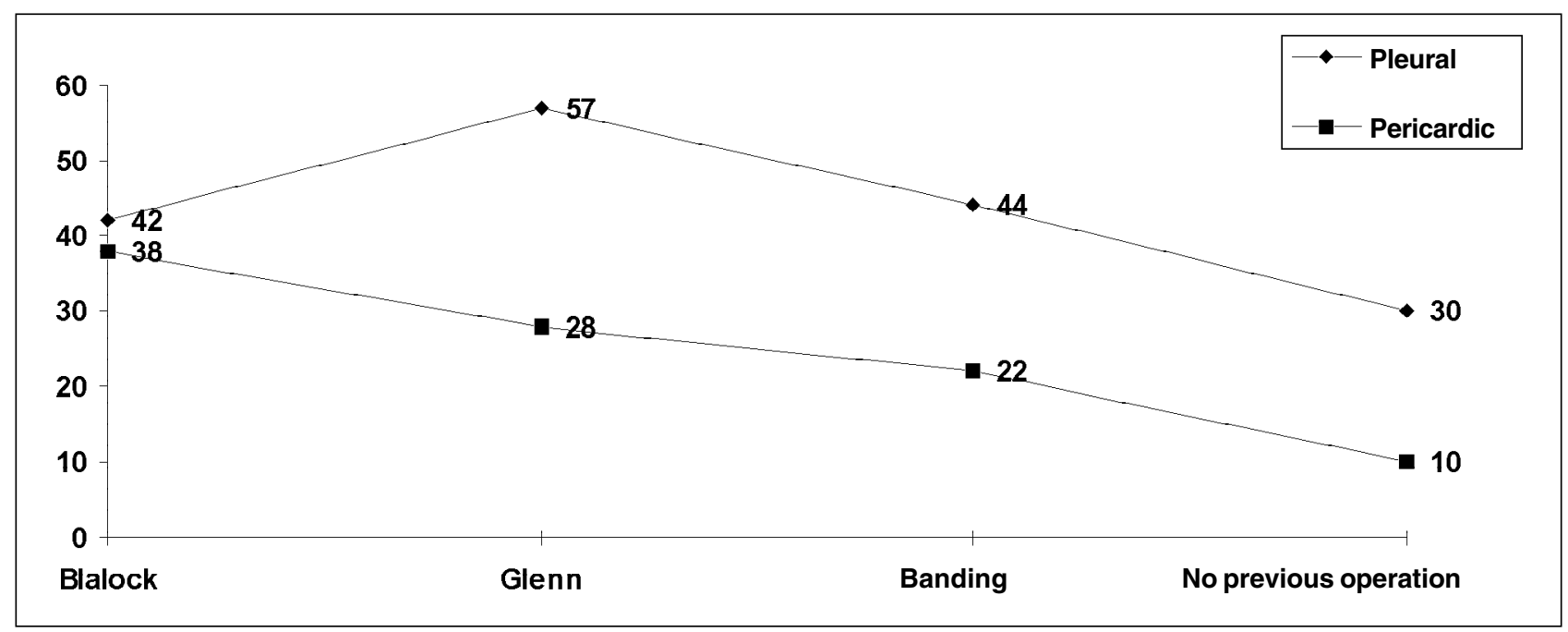

Fig. 1 - Significant pleural and pericardial effusion (\%) in immediate postoperative cavopulmonary technique in relation to the presence or absence of previous operations.

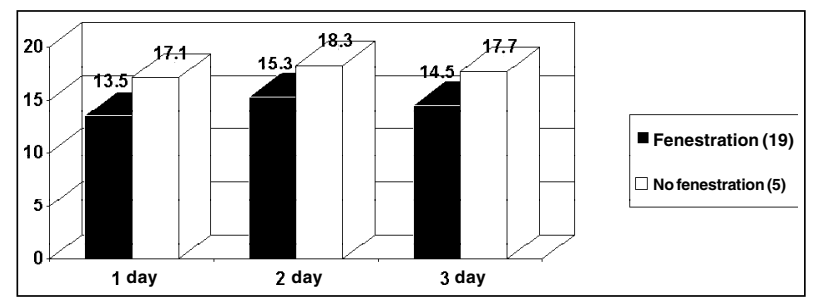

Fig. 2 - Central mean venous pressure $\left(\mathrm{cm} \mathrm{H}_{2} \mathrm{O}\right)$, in the first 3 days, of patients who underwent the cavopulmonary technique with and without atrial fenestration.

Significant cardiac murmurs occurred in 3 patients, all from group I. Sinus rhythm was present in $94 \%$ of the cases, with right atrium ectopic beats in 2 patients, both from group I. Normalization of the $\mathrm{P}$ wave occurred in all patients in the postoperative period in relation to that observed in the preoperative period, changing from a mean value of $3 \mathrm{~mm}$ to $1.6 \mathrm{~mm}$.

In 17 patients undergoing imaging with a technetium $99 \mathrm{~mm}$ labeled agent, pulmonary arteriovenous fistulas was not detected and pulmonary perfusion was similar in both lungs from both groups.
Echocardiography showed normal ventricular function in all patients.

Ergospirometry performed in 11 patients showed that patients had good physical tolerance with a duration of mean effort on the treadmill of 14 minutes and 4 seconds and with a maximum mean oxygen consumption $\left(\mathrm{VO}_{2}\right)$ of $27.9 \mathrm{~mL} / \mathrm{kg}^{-1} \cdot \mathrm{min}^{-1}$, ranging from 22.6 to $33.9 \mathrm{ml} / \mathrm{kg}^{-1} \cdot \mathrm{min}^{-1}$. The anaerobic threshold was reached after 5 minutes and 8 seconds, with heart rate of $133 \mathrm{bpm}$ and with $\mathrm{VO}_{2}$ of $18.7 \mathrm{~mL} /$ $\mathrm{kg}^{-1} \cdot \mathrm{min}^{-1}$. Respiratory decompensation was reached after 10 minutes and 7 seconds with $\mathrm{VO}_{2}$ of $26.7 \mathrm{~mL} / \mathrm{kg}^{-1} \cdot \mathrm{min}^{-1}$ and a heart rate of $165 \mathrm{bpm}$. Systolic arterial pressure increased on average $25.7 \mathrm{mmHg}$.

Anticongestive, antithrombotic medication, or both, had been administered to $19(30.6 \%)$ of 62 patients, 15 patients $(36.5 \%)$ of which were from group I.

\section{Discussion}

Systemic congestive events and thromboembolic events, electrical disturbances, as well as arteriovenous pulmonary fistula that usually appear in postoperative fol- 


\begin{tabular}{|c|c|c|c|c|c|c|c|c|c|c|c|c|c|c|}
\hline \multirow[t]{2}{*}{ Diagnosis } & \multirow[t]{2}{*}{$\mathrm{N}$} & \multirow[t]{2}{*}{ Cyanosis } & \multicolumn{2}{|c|}{ NYHA } & \multicolumn{2}{|c|}{ Murmmur } & \multicolumn{3}{|c|}{ Liver (cm) } & \multicolumn{3}{|c|}{ Sat $\mathrm{O}_{2}(\%)$} & \multicolumn{2}{|c|}{$\mathrm{Hg}$} \\
\hline & & & I & II & + & + & 0 & $<2$ & $>2$ & $>70$ & $>80$ & $>90$ & $<15$ & $>17$ \\
\hline Tricuspid Atresia & 26 & 4 & 24 & 2 & 4 & 1 & 25 & 1 & - & 2 & 2 & 22 & 22 & 4 \\
\hline Fenestrated & 23 & 4 & 21 & 2 & 4 & 1 & 22 & 1 & & 2 & 2 & 19 & 19 & 4 \\
\hline Nonfenestrated & 3 & - & 3 & - & - & - & 3 & - & - & & & 3 & 3 & - \\
\hline Single ventricle & 25 & 1 & 22 & 3 & 6 & 1 & 22 & 2 & 1 & - & 1 & 24 & 23 & 2 \\
\hline Fenestrated & 11 & 1 & 9 & 2 & 3 & 1 & 9 & 1 & 1 & - & 1 & 10 & 9 & 2 \\
\hline Nonfenestrated & 14 & - & 13 & 1 & 3 & - & 13 & 1 & - & - & - & 14 & 14 & - \\
\hline Others & 11 & - & 11 & - & 4 & 1 & 8 & 2 & 1 & - & 11 & 11 & - & \\
\hline Fenestrated & 7 & - & 7 & - & 3 & 1 & 5 & 2 & - & - & - & 7 & 7 & - \\
\hline Nonfenestrated & 4 & - & 4 & - & 1 & - & 3 & - & 1 & - & - & 4 & 4 & - \\
\hline Total & 62 & 5 & 57 & 5 & 14 & 3 & 55 & 5 & 2 & 2 & 3 & 57 & 56 & 6 \\
\hline Fenestrated & 41 & 5 & 37 & 4 & 10 & 3 & 36 & 4 & 1 & 2 & 3 & 36 & 35 & 6 \\
\hline Nonfenestrated & 21 & - & 20 & 1 & 4 & - & 19 & 1 & 1 & - & - & 21 & 21 & \\
\hline
\end{tabular}

low-up of the atriopulmonary technique of Kreutzer et al ${ }^{7}$, in the atrioventricular technique of Bjork et al ${ }^{8}$, caused us to use and consolidate another technique, the cavopulmonary technique idealized by Puga et al ${ }^{1}$, by Leval et $\mathrm{al}^{2}$ and by Jonas and Castaneda ${ }^{3}$.

New techniques, such as the cavopulmonary technique, became necessary to decrease the follow-up risks before ventricular dysfunction, which worsen these patients' conditions. The factors that require this technical change were well demonstrated by Conte et $\mathrm{al}^{9}$ in 7 patients with physical intolerance including great dilation of right atrium, atrial arrhythmia, congestive events, and protein-losing enteropathy. Marcelletti et al ${ }^{10}$ also demonstrated in 31 patients, atrial arrhythmia in 20, heart failure in 17, previous Fontan obstruction in 10 , serosal effusion in 10 , protein-losing enteropathy in 3 and right atrium thrombosis in 2 patients.

Other technical modifications made cavopulmonary anastomosis even more suitable, both for immediate postoperative evolvement with decreased systemic venous hypertension and congestive events through atrial fenestration ${ }^{4}$, and for late follow-up through the placement of an extracardiac conduit ${ }^{5}$ from the inferior vena cava to the right pulmonary artery, instead of an intraatrial tunnel.

This extracardiac technique may also help in immediate evolvement, decreasing mean time of thoracic drainage, even in the absence of fenestration, which was performed in $24(47 \%)$ of the 51 patients evaluated by Petrossian et al ${ }^{11}$. This benefit was also shown by Lardo et al ${ }^{12}$.

The decrease in venous pressure with fenestration between the right and left atrium enables, in theory, a smaller incidence of systemic congestive events, such as serosal effusion and hepatomegaly, mainly in early follow-up althrough presence of systemic arterial insaturation. However, in contrast, even though a clear smaller central venous pressure occurred in patients with atrial fenestration, serosal effusion, such as pleural and pericardial effusion, occurred more significantly in this group of patients.

It is possible that other factors are involved in the occurrence of congestive events. First of all is the anatomical and functional condition of the cardiopathy and the patient's age: the older the patient the more probable the presence of degenerating events. Previous palliative operations also contribute to the worsening of myocardial function.

In our study, the mean age was high at the time of operation and a clear correlation existed between the intensity of effusions with the operation previously performed. Significant pleural effusion occurred in $42 \%$ of patients who previously underwent a Blalock Taussig procedure, in $44 \%$ of patients who underwent previous pulmonary banding, in $57 \%$ of patients who underwent a bidirectional Glenn procedure, as opposed to $30 \%$ of patients in whom no palliative procedure had been performed.

We concluded that fenestration may be of a great benefit since no significant anatomical and functional alterations has occurred and mostly when the operation is performed at an early age and in the absence of adverse degenerating events and when patients have not undergone previous operations, especially those of long-term surgery.

Late follow-up of the nonfenestrated group in our study enabled us to assess them favorably, regarding the absence of electrical alterations, such as alteration of the cardiac rhythm, the appearance of pulmonary arteriovenous fistulas and the occurrence of congestive events like hepatomegaly. These alterations are very frequent at the time of follow-up of other techniques and modification of the Fontan procedure.

Good tolerance to physical effort found in our patients demonstrates this better evolvement, in contrast with the findings of other authors, whose patients' oxygen consumption assessed through ergospirometry was significantly reduced after the Fontan operation, compared with that in other children operated on with other corrective techniques, such as Senning and Mustard procedures or after the repair of tetralogy of Fallot ${ }^{13}$.

It is necessary to mention, however, that the physical capacity is related to the Fontan operation being performed at an early age, also in the absence of volume overload imposed by previous palliative operations. In the subgroup of 
patients who underwent the technique early, before 2 years of age, the consumption of oxygen $\left(\mathrm{VO}_{2}\right.$ maximum) reached was $88.6 \pm 24.1 \%$, according to Mahle et al ${ }^{6}$.

Some patients experience unfavorable events of atrial fenestration in late follow-up, such as peripheral arterial insaturation and cyanosis, with consequent elevation of hematocrit and the decrease in physical tolerance. These elements may be successfully corrected by occluding the interatrial communication with a prostheses ${ }^{14}$.

Thus, generally, with or without fenestration, cavopulmonary anastomosis seems to be the most suitable for the Fontan technique, due to the good evolvement because the criteria for indication of operation are followed.

Through this technique, congestive, electrical and thromboembolic events and alterations in hepatic function or coagulation are minimized compared with that which occurs with other technical variations.

In the presence of hepatic congestion, even though protein synthesis is normal, important alterations occur in coagulation mainly in $\mathrm{V}$ and VII factors with prolonged prothrombin activity and cholestase. In these cases, the use of systematic anticoagulant therapy is recommended according to Van Nieuwenhuizen et al ${ }^{15}$.

In conclusion, it seems that fenestration does not act favorably in early or late follow-up and is therefore dis- pensable. According to some authors ${ }^{16}$, it could be performed systematically to obtain greater efficiency in the presence of the risks of the Fontan operation, when the mean pressure of the pulmonary artery exceeds $15 \mathrm{mmHg}$, pulmonary resistance is greater than $2 \mathrm{U}$ Wood, or if ventricular dysfunction with ejection fraction lower than $60 \%$ is present, with final diastolic pressure of the left ventricle greater than $8 \mathrm{mmHg}$. The same occurs when the pulmonary arteries have smaller diameters, evaluated by the McGoon index lower than 1.5 , or by the Nakata index lower than $200 \mathrm{~mm}^{2} / \mathrm{m}^{2}$, according to Marroquin et al ${ }^{17}$, although in these cases mortality has reached $23 \%$.

Takeda et al ${ }^{18}$ also showed greater mortality, 4 (25\%) of 16 patients. In the greater risk group, however, they emphasized the usefulness of fenestration, which becomes definitive in these cases.

Because of all the factors discussed here, it is important to avoid degenerative events caused by cardiopathy, especially those that occur after long duration palliative operations, that have a negative influence in the late follow-up of these patients.

\section{Acknowledgments}

To Dr. Luis Felipe Moreira for the statistical support.

\section{References}

1. Puga FJ, Chiavarelli M, Hagler DJ. Modifications of the Fontan operation applicable to patients with left atrioventricular valve atresia or single atrioventricular valve. Circulation 1987; 76( suppl III): III 53-60.

2. De Leval MR, Kilner P, Gewillig M, Bull C, McGoon DC. Total cavopulmonary connection: a logical alternative to atriopulmonary connection for complex Fontan operations. Experimental studies and early clinical experience. J Thorac Cardiovasc Surg 1988; 96: 682-95.

3. Jonas RA, Castaneda AR. Modified Fontan procedure: atrial baffle and systemic venous to pulmonary artery anastomotic techniques. J Card Surg 1988; 3: 91-6.

4. Lacks H, Haas GS, Pearl MJ, Sadeghi AM, George B, Santuli TV, Williams RG. The use of an adjustable intraatrial communication in patients undergoing the Fontan and other definitive heart procedures. Circulation 1988; 78( suppl 2): 357.

5. Amodeo A, Galletti L, Marianeschi S, Picardo S, Giannico S, Di Renzi P, Marcelletti CF. Extracardiac Fontan operation for complex cardiac anomalies: seven years' experience. J Thorac Cardiovasc Surg 1997; 114: 1020-30.

6. Mahle WT, Wernovsky G, Bridges ND, Linton AB, Paridon SM. Impact of early ventricular unloading on exercise performance in preadolescents with single ventricle Fontan physiology. J Am Coll Cardiol 1999; 34: 1637-43.

7. Kreutzer G, Galindez E, Bono H, de Palma C, Laura JP. An operation for the correction of tricuspid atresia. J Thorac Cardiovasc Surg 1973; 66: 613-21.

8. Bjork VO, Olin CL, Bjarke BB, Thoren CA. Right atrial-right ventricular anastomosis for correction of tricuspid atresia. J Thorac Cardiovasc Surg 1979; 77: 452-8.

9. Conte S, Gewillig M, Eyskens B, Dumoulin M, Daenen W. Management of late complications after classic Fontan procedure by conversion to total cavopulmonary connection. Cardiovasc Surg 1999; 7: 651-5.
10. Marcelletti CF, Hanley FL, Mavroudis C, et al. Revision of previous Fontan connections to total extracardiac cavopulmonary anastomosis: a multicenter experience. J Thorac Cardiovasc Surg 2000; 119: 340-6.

11. Petrossian E, Reddy VM, McElhinney DB, et al. Early results of the extracardiac conduit Fontan operation. J Thorac Cardiovasc Surg 1999; 117: 688-96.

12. Lardo AC, Webber SA, Friehs I, del Nido PJ, Cape EG. Fluid dynamic comparison of intra-atrial and extracardiac total cavopulmonary connections. J Thorac Cardiovasc Surg 1999; 117: 697-704.

13. Mocellin R, Gildein P. Velocity of oxigen uptake response at the onset of exercise: a comparison between children after cardiac surgery and healthy boys. Pediatr Cardiol 1999; 20: 17-20.

14. Tofeig M, Walsh KP, Chan C, Ladusans E, Gladman G, Arnold R. Occlusion of Fontan fenestrations using the Amplatzer septal occluder. Heart 1998; 79: 368-70.

15. Van Nieuwenhuizen RC, Peters M, Lubbers LJ, Trip MD, Tijssen JG, Mulder BJ. Abnormalities in liver function and coagulation profile following the Fontan procedure. Heart 1999; 82: 40-6.

16. Thompson LD, Petrossian E, McElhinney DB, et al. Is it necessary to routinely fenestrate an extracardiac Fontan? J Am Coll Cardiol 1999; 34: 539-44.

17. Ramirez Marroquin S, Calderon Colmenero J, Lince Varela R, ZabalC, Rijlaarsdam M, Buendia A. Fenestrated Fontan surgery in high risk patients. Arch Inst Cardiol Mex 1998; 68: 377-82.

18. Takeda M, Shimada M, Sekiguchi A, Ishizawa A. Long-term results of the fenestrated Fontan operation: progress of patients with patent fenestrations. Jpn J Thorac Cardiovasc Surg 1999; 47: 432-9. 